\title{
Comportamento ingestivo de vacas em lactação em diferentes sistemas forrageiros
}

\author{
Clair Jorge Olivo, Magnos Fernando Ziech², Gilmar Roberto Meinerz², José Francisco Both², \\ Carlos Alberto Agnolin², Tiago Vendrame ${ }^{2}$
}

\footnotetext{
${ }^{1}$ Departamento de Zootecnia - Universidade Federal de Santa Maria (UFSM), Campus Camobi, CEP: 97105-900, Santa Maria, RS, Brasil ${ }^{2}$ Curso de Zootecnia da UFSM, Santa Maria, RS, Brasil.
}

\begin{abstract}
RESUMO - Estudou-se o comportamento alimentar de vacas da raça Holandesa em lactação mantidas em pastagem de misturas de espécies de capim-elefante (Pennisetum purpureum Schum.), azevém (Lolium multiflorum Lam.) e outras de crescimento espontâneo. Como diferencial destas pastagens, introduziu-se trevo-branco (Trifolium repens L.) ou amendoim forrageiro (Arachis pintoi Krapov. \& Greg.). Nos meses de julho, agosto e outubro de 2005, foram feitas avaliações em pastejo utilizando-se em cada uma seis vacas entre o segundo e o quinto mês de lactação, observadas nos períodos de 18 às 6 h e de 8 às 16 h, a cada 10 minutos, por dois observadores. Foram observados o tempo de pastejo nas linhas constituídas por capim-elefante (CE), o tempo de pastejo nas espécies estabelecidas na entrelinha e os tempos de pastejo total (pastejo de CE + entrelinha), ruminação e ócio. Também foram avaliados a massa de forragem inicial, o valor nutritivo da forragem ingerida e as condições climáticas do período. O tempo médio de pastejo na entrelinha foi de 4 horas e 9 minutos para o trevo-branco e de 3 horas e 6 minutos para o amendoim forrageiro. O tempo médio de pastejo do capim-elefante não diferiu entre as misturas com trevo-branco (4 horas e 27 minutos) e com amendoim forrageiro (5 horas e 51 minutos), assim como os tempos de ruminação e ócio, que também não diferiram entre as espécies associadas. A presença de forrageiras de inverno está associada ao maior tempo de consumo de forragem. A presença de espécies de ciclos diferentes possibilitou que os animais equilibrassem a dieta volumosa.
\end{abstract}

Palavras-chave: amendoim forrageiro, azevém, capim-elefante, etologia, trevo-branco

\section{Ingestive behavior of dairy cows in different systems fodder}

\begin{abstract}
The objetive of this research was to study the eating behavior of lactating Holstein cows grazing mixed species of elephant grass (Pennisetum purpureum Schum.), ryegrass (Lolium multiflorum Lam.) and others spontaneous growth species. As differential of these pastures, was introduced white clover (Trifolium repens L.) or peanut forage (Arachis pintoi Krapov. \& Greg.). Grazing eating behavior evaluations were taken on July, August and October of 2005. In each grazing eating behavior evaluation, six cows, between the second and fifth month of lactation, were observed in the periods from 18 to $6 \mathrm{~h}$ and 8 to 16 hours, every 10 minutes, by two observers. Grazing time of elephant grass (EG) in lines, grazing time of introduced species, established in interlines, and time of total grazing (EG grazing + interlines), rumination and idle were evaluated. Also, were evaluated the initial herbage mass, nutritional value of ingested forage and climatic conditions in the period. Grazing mean time in interline was 4 hours and 9 minutes for white clover and 3 hours and 6 minutes for peanut forage. Grazing mean time for elephant grass did not differ among the mix with white clover (4 hours and 27 minutes) and with peanut forage (5 hours and 51 minutes) as for rumination time and idle, which also did not differ among introduced species. The presence of winter forage is associated to the higher time of forage intake. The presence of species of different cycles enabled the animals to balance the forage diet.
\end{abstract}

Key Words: elephant grass, ethology, forage peanut, ryegrass, white clover

\section{Introdução}

Entre os fatores que afetam o comportamento ingestivo dos bovinos leiteiros, destacam-se o clima, a alimentação e o sistema de produção (Grant \& Albright, 1995; Brâncio et al., 2003). O conhecimento das atividades realizadas e dos hábitos alimentares contribui para a melhoria do bem-estar e do desempenho dos animais, tanto daqueles mantidos em confinamento quanto daqueles em pastejo (Gonyou, 1994; Polli et al., 1995; Brâncio et al., 2003; Costa et al., 2003; Mendonça et al., 2004; Perissinotto et al., 2006; Trevisan et al., 2005). 
As principais variáveis comportamentais estudadas são aquelas relacionadas às atividades de alimentação, ruminação, ócio e procura por água (Ray \& Roubicek, 1971).

O gado leiteiro pode modificar o comportamento de acordo com o tipo, a quantidade e acessibilidade do alimento e às práticas de manejo (Fischer et al., 2002). A produção, o horário e o número de ordenhas são condições determinantes dos padrões de comportamento de vacas em lactação (Balocchi et al., 2002). Em condições de pastejo, a quantidade de matéria seca (MS) e a disponibilidade de folhas verdes acessíveis na superfície da pastagem afetam o tempo de permanência dos ruminantes na busca e colheita de alimento (Trevisan et al., 2005). A facilidade de apreensão da forragem é um dos fatores que determinam o aumento ou a redução no tempo de pastejo, alterando os tempos de ruminação e ócio (Carvalho et al., 2001).

Em pastejo rotacionado, especialmente em ofertas de forragem média e alta, há redução na disponibilidade de forragem e mudanças na composição estrutural das plantas, notadamente na proporção folha/colmo, o que pode afetar o comportamento ingestivo e a produção animal (Chacon \& Stobbs, 1976). Em forrageiras tropicais, como o capimelefante (CE), a massa de forragem é mais fibrosa e de mais baixa qualidade em comparação a forragens de clima temperado, o que pode limitar o consumo (Stobbs, 1973).

Pesquisas sobre o comportamento animal em pastagens de capim-elefante consorciadas com gramíneas hibernais e leguminosas são escassas. Trabalhos desta natureza são importantes para identificar a preferência dos animais na composição da dieta e agregar informações úteis à perenização das espécies para otimização do sistema forrageiro. Considerando as características climáticas da Região Sul, a utilização de espécies anuais de ciclo hibernal e leguminosas em consórcio com espécies perenes de ciclo estival pode ser vantajosa, pois viabiliza a utilização de pastagens no decorrer do ano agrícola e a racionalização dos insumos na mesma área.

Assim, objetivou-se com este trabalho estudar, durante o período hibernal, o comportamento ingestivo de vacas em lactação em pastagens de capim-elefante e azevém consorciadas com trevo-branco ou amendoim forrageiro.

\section{Material e Métodos}

O trabalho foi conduzido no Laboratório de Bovinocultura de Leite, pertencente ao Departamento de Zootecnia da UFSM, situado na região da Depressão

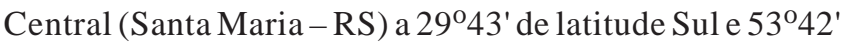
de longitude Oeste, com clima subtropical úmido (Moreno, 1961). A precipitação anual varia de 1.300 a 1.800 mm e a temperatura média é de $19,2^{\circ} \mathrm{C}$. O solo é classificado como argissolo vermelho distrófico arênico (Embrapa, 1999).

A área utilizada (1,0 ha) foi dividida em quatro piquetes (0,25 ha), de modo que o capim-elefante (Pennisetum purpureum Schum.), cv. Merckeron pinda, constituiu a base do sistema forrageiro. O capim-elefante foi estabelecido em linhas afastadas a cada $4 \mathrm{~m}$, entre os anos de 2002 e 2003. Em dezembro de 2004, nas entrelinhas, foi implantado em metade da área (dois piquetes) o amendoim forrageiro (Arachis pintoi Krapov. \& Greg.), cv. Amarillo, com densidade de semeadura de $12 \mathrm{~kg} / \mathrm{ha}$. Na outra metade, em junho de 2005, mediante escarificação do solo, foram estabelecidos o trevo-branco (Trifolium repens L.), cv. Yi, em densidade de $4 \mathrm{~kg} / \mathrm{ha}$, e o azevém (Lolium multiflorum Lam.), cv. Comum, em densidade $40 \mathrm{~kg} / \mathrm{ha}$. Na área estabelecida com amendoim forrageiro, a implantação do azevém (40 kg/ha) foi realizada por sobressemeadura. Durante todo o período de avaliação, permitiu-se o desenvolvimento de espécies de crescimento espontâneo.

Para adubação, foram utilizados fósforo ( $40 \mathrm{~kg} / \mathrm{ha} / \mathrm{ano}$ ) de fósforo e potássio (40 kg/ha/ano) conforme análise de solo e recomendação para as leguminosas perenes usadas (Manual de adubação e calagem para os estados do Rio Grande do Sul e Santa Catarina, 2004). No período, realizou-se adubação com nitrogênio em forma de uréia, na proporção de $50 \mathrm{~kg} / \mathrm{ha} / \mathrm{ano}$, divididos em duas aplicações.

Como tratamentos, avaliaram-se dois sistemas forrageiros: um de capim-elefante + trevo branco + azevém + espécies de crescimento espontâneo (SF1); e outro de capim-elefante + amendoim forrageiro + azevém + espécies de crescimento espontâneo (SF2). As observações de cada sistema forrageiro foram realizadas em três ciclos de pastejo, conduzidos em julho, setembro e outubro. Avaliaram-se o tempo despendido com pastejo na entrelinha, o tempo de pastejo de capim-elefante, o tempo de pastejo total dos materiais (das entrelinhas + capim-elefante) e os tempos de ruminação e ócio. Em cada avaliação, utilizaram-se seis vacas da raça Holandesa entre o segundo e o quinto mês de lactação, com $517 \pm 43,2 \mathrm{~kg}$ de peso corporal e produção de $18 \pm 2,7 \mathrm{~kg} / \mathrm{dia}$, recebendo suplementação alimentar diária de 3,5 kg de concentrado com 20\% de PB e 3,5 kg de MS de silagem de milho, fornecidos após as ordenhas (manhã e tarde). As vacas foram mantidas nas pastagens das 8 às 16 h e das 18 às 6 h, com sombra, água e sal mineral à disposição.

As observações foram realizadas em turnos de 4 horas, por dois avaliadores a cada 10 minutos, durante 20 horas diárias. As vacas eram retiradas da pastagem duas vezes ao dia para as ordenhas da manhã e da tarde, quando também recebiam a suplementação alimentar. 
Como critério de utilização da pastagem, consideraram-se as espécies estabelecidas na entrelinha. A utilização da pastagem se iniciou quando o pasto apresentava aproximadamente $20 \mathrm{~cm}$ de altura. Para determinar a carga animal, procurou-se manter a oferta de MS entre 8 e $10 \mathrm{~kg}$ para a entrelinha e de $4 \mathrm{~kg}$ por $100 \mathrm{~kg}$ de peso vivo para a biomassa de lâminas foliares de capim-elefante (linha), com base na massa de forragem inicial da pastagem, estimada pela técnica de dupla amostragem (Wilm et al., 1944), efetuando-se cinco cortes na entrelinha (rente ao solo) e na linha (cortes a $50 \mathrm{~cm}$ do solo). Nos cálculos, considerou-se que $25 \%$ da área era ocupada pelo capim-elefante (linha) e 75\% pela entrelinha. Para determinar a qualidade da pastagem, foram retiradas em cada avaliação amostras de simulação de pastejo (Euclides et al., 1992) e, isoladamente, amostras do capim-elefante e da entrelinha no momento da entrada e da saída dos animais. As amostras foram secas, moídas e analisadas para determinação dos teores de proteína bruta (PB), pelo método de Kjeldahl (AOAC, 1984), e fibra em detergente neutro (FDN), segundo Van Soest et al. (1991), e da digestibilidade in vitro da matéria seca (DIVMS), conforme descrito por Tilley \& Terry (1963). Os valores de digestibilidade in vitro da matéria orgânica (DIVMO) foram utilizados para estimar o teor de nutrientes digestivíveis totais (NDT) das pastagens, conforme a equação: NDT = MO $\{[26,8+0,595$ (DIVMO) $] / 100\}$, descrita por Kunkle \& Bates (1998), na qual NDT = nutrientes digestíveis totais (\%); MO = matéria orgânica (\%); e DIVMO = digestibilidade in vitro da matéria orgânica (\%).

O delineamento experimental foi inteiramente casualizado com dois tratamentos (sistemas forrageiros) e seis repetições (vacas). Para análise dos dados, utilizou-se o procedimento MIXED(SAS, 1997), considerando um modelo misto. O modelo analítico incluiu o efeito do tratamento e dos pastejos e as respectivas interações. A matriz de variância e co-variância usada foi de estrutura heterogênea de primeira ordem auto-regressiva (ARH (1)). As variáveis que apresentaram interação sistema forrageiro $\times$ pastejo foram submetidas à análise de regressão polinomial a 5\%. Os dados ambientais, da pastagem e da produção animal, levantados juntamente com os parâmetros comportamentais, foram usados para análise de correlação.

O modelo estatístico foi representado por Yijk $=\mu+\mathrm{Ti}$ $+\mathrm{Rj}(\mathrm{Ti})+\mathrm{Pk}+\mathrm{TiPk}+$ eijk; em que Yijk = variáveis dependentes; $\mu$ = média de todas as observações; $\mathrm{Ti}=$ efeito dos sistemas forrageiros; $\mathrm{Rj}$ = efeito das repetições (vacas); $\mathrm{Rj}(\mathrm{Ti})$ = efeito da j-ésima repetição dentro do i-ésimo sistema forrageiro (erro A); $\mathrm{Pk}=\mathrm{k}$-ésimo efeito dos pastejos; TiPk = interação sistema forrageiro $\times$ pastejo; e $\varepsilon i j k=$ erro experimental residual (erro B).

\section{Resultados e Discussão}

Houve diferença significativa $(\mathrm{P}<0,05)$ para a massa de forragem do capim-elefante, que foi maior no sistema com amendoim forrageiro (Tabela 1). Considerando, no entanto, a massa de forragem de lâminas do capim-elefante, uma variável mais representativa da pastagem, houve similaridade $(\mathrm{P}>0,05)$ entre os sistemas forrageiros. Para as composições botânica, estrutural e de valor nutritivo, também não houve diferença significativa entre os sistemas forrageiros. Mesmo havendo espécies de ciclos diferentes (trevo-branco e amendoim forrageiro), verificou-se similaridade no manejo dos sistemas forrageiros com a oferta de matéria seca média próxima a $8 \mathrm{~kg} / \mathrm{vaca} / \mathrm{dia}$ e, embora o capim-elefante tenha ocupado área menor, sua participação na pastagem foi de aproximadamente $70 \%$.

Na primeira avaliação, houve diferença $(\mathrm{P}<0,05)$ para o tempo de pastejo dos animais na entrelinha (Tabela 2), que foi maior no sistema forrageiro com trevo-branco. Esse resultado está relacionado à maior presença de lâminas foliares e, proporcionalmente, à menor participação de colmos de azevém, além da menor participação de outras espécies e de material morto neste sistema. Esse comportamento pode ser atribuído ao manejo utilizado, uma vez que foi realizada a escarificação do solo (entrelinha) para a semeadura do azevém e do trevo-branco, enquanto, no sistema forrageiro com amendoim forrageiro, fez-se a sobresemeadura do azevém. Como conseqüência, houve retardamento na participação dessa espécie, em razão da presença do amendoim forrageiro e da persistência de outras espécies de ciclo estival (Tabela 1).

Entre os sistemas de pastejo, o comportamento foi similar. Houve efeito quadrático crescente $(\mathrm{P}<0,05)$ para essa variável, em virtude da maior participação do azevém na composição da pastagem (Figura 1). No sistema forrageiro com trevo-branco, a presença dessa forrageira influenciou o comportamento das vacas que, em média, disponibilizaram mais tempo na entrelinha (Tabela 2), confirmando a maior preferência dos animais por forrageiras de ciclo hibernal em relação às de ciclo estival (Stobbs, 1978).

As correlações entre o teor de proteína bruta e a massa de forragem de trevo-branco $(0,9993 ; \mathrm{P}=0,0228)$ e a de amendoim forrageiro $(-0,9985 ; \mathrm{P}=0,0340)$ confirmam essa informação. No sistema com amendoim forrageiro, a correlação observada entre o tempo de pastejo na entrelinha e o número de geadas cumulativas $(-0,9999 ; \mathrm{P}=0,0034)$ permite sugerir que, com o crestamento das folhas do amendoim forrageiro, houve menor acesso dos animais nessa área de pastagem. Esses resultados influenciaram significativamente $(\mathrm{P}<0,05)$ o tempo médio gasto pelos animais em 
Tabela 1 - Componentes botânicos do capim-elefante (CE) e das principais espécies presentes na entrelinha, massa de forragem inicial, valor nutritivo do pasto e carga animal

Componentes estruturais e botânicos (\%)

\%) Período

Julho de $2005 \quad$ Agosto de 2005

Lâmina foliar capim-elefante

SF1

SF2

SF1

SF2

Outubro de 2005

Média

Colmo capim-elefante

Material morto capim-elefante

$40,5 \quad 33,5$

$52,5 \quad 55,0$

21,0

$7,0 \quad 11,5$

61,0

$\begin{array}{ll}7,0 & 11,5 \\ 7,5 & 25,0\end{array}$

18,0

$7,5 \quad 5,0$

54,0

Colmo do azevém

7,5

5,0

19,5

17,0

Amendoim forrageiro

Material morto (entrelinha)

11,0

7, 0

$2,0 \quad 13,0$

-

25,0

13,0
50,0

1,5

8,0

19,0

66,0

15,0

46,0

22,0

$-$

7, 0

10,0

15,0

SF1

SF2

25,0

57,0

19,0

63,5

17,5

25,0

16,0

58,0

57,0

-

4, 0

$12,0 \quad 9,0$

9,0
13,0

13,0

$1,90 \quad 2,76$

0,51

1,21

1,87

1,21
3,97

3,77

3,63

2,59

19,1

42, 6

91,7

18,4

45,0

89,1

72,2

71,9

18,4

18,4

44,2

80,7

65,6

15,5
52,5
76,3

52,5
76,3

63,5

$\begin{array}{cc}2,1^{\mathrm{b}} & 3,0^{\mathrm{a}} \\ 0,6 & 0,7 \\ 0,9 & 0,8 \\ 3,0 & 3,9\end{array}$

Nutrientes digestíveis totais

$62,5 \quad 59,6$

Carga animal (t peso vivo/ha)

Carga animal instantânea

28,2

38,1

18,6

22,0

29,0

24,9

25,3

$18,9 \quad 17,2$

$45,7 \quad 49,6$

$83,1 \quad 78,7$

$66,7 \quad 65,0$

'a b'médias dos tratamentos com letras distintas, na linha, diferem $(P<0,05)$ entre si pelo teste $F$.

SF1- capim-elefante + trevo branco + azevém + espécies de crescimento espontâneo.

SF2 - capim-elefante + amendoim forrageiro + azevém + espécies de crescimento espontâneo.

DIVMS - digestibilidade in vitro da matéria seca.

1- amostras coletadas por simulação de pastejo.

Tabela 2 - Dados comportamentais (\%) de vacas em lactação, em 20 horas diárias, manejadas nos sistemas forrageiros

\begin{tabular}{|c|c|c|c|c|c|c|c|}
\hline Tempo de pastejo & Sistema forrageiro & \multicolumn{3}{|c|}{ Período } & Efeito & Média & CV (\%) \\
\hline \multirow[t]{2}{*}{ Entrelinha } & SF1 & $15,40 b \pm 1,96$ & $32,20 \mathrm{a} \pm 2,03$ & $14,74 b \pm 2,13$ & \multirow[t]{2}{*}{$\mathrm{T} ; \mathrm{P} ; \mathrm{T} \times \mathrm{P}$} & $20,78 \mathrm{~A}$ & \multirow[t]{2}{*}{34,99} \\
\hline & SF2 & $6,83 \mathrm{c} \pm 1,96$ & $24,86 a b \pm 2,03$ & $14,82 b \pm 2,13$ & & $15,50 \mathrm{~B}$ & \\
\hline Capim-elefante & SF1 & $32,31 \mathrm{a} \pm 2,17$ & $12,85 b \pm 2,61$ & $36,50 \mathrm{a} \pm 3,86$ & $\mathrm{~T} \times \mathrm{P}$ & 27,22 & 18,94 \\
\hline \multirow[t]{2}{*}{ Pastejo total } & SF1 & $47,72 \mathrm{ab} \pm 1,96$ & $45,06 b \pm 1,85$ & $51,24 a \pm 2,39$ & \multirow[t]{2}{*}{$\mathrm{T} \times \mathrm{P}$} & 48,00 & \multirow[t]{2}{*}{10,28} \\
\hline & SF2 & $42,90 \mathrm{~b} \pm 1,96$ & $47,40 \mathrm{ab} \pm 1,85$ & $45,96 a b \pm 2,39$ & & 45,42 & \\
\hline \multirow[t]{2}{*}{ Ruminação } & SF1 & $36,89 b \pm 1,89$ & $42,94 a \pm 1,27$ & $37,19 b \pm 1,23$ & \multirow[t]{2}{*}{$\mathrm{T} \times \mathrm{P}$} & 39,00 & \multirow[t]{2}{*}{10,77} \\
\hline & SF2 & $39,05 a b \pm 1,89$ & $37,43 a b \pm 1,27$ & $38,52 b \pm 1,23$ & & 38,33 & \\
\hline Ócio & SF1 & $15,38 \pm 1,93$ & $12,00 \pm 2,01$ & $11,57 \pm 2,03$ & & 12,98 & 27,74 \\
\hline
\end{tabular}

'a b' médias seguidas por letras distintas nas linhas e nas colunas diferem $(P<0,05)$ entre si pelo teste $F$.

'A B' médias seguidas de letras distintas na coluna diferem $(P<0,05)$ entre si pelo teste $F$.

SF1 = capim-elefante + trevo branco + azevém + espécies de crescimento espontâneo; SF2 = capim-elefante + amendoim forrageiro + azevém + espécies de crescimento espontâneo.

CV: coeficiente de variação. 
SF1

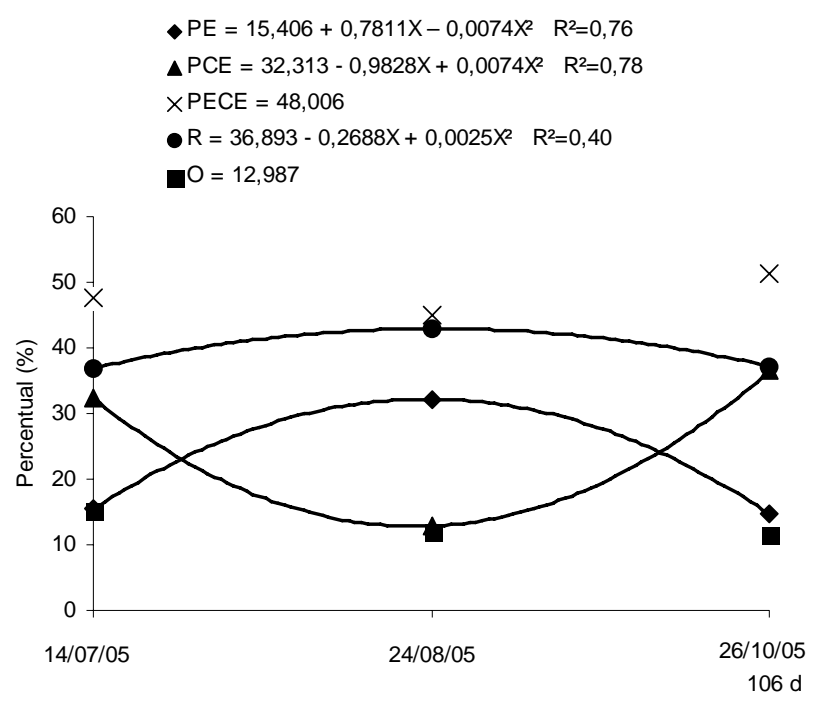

SF2

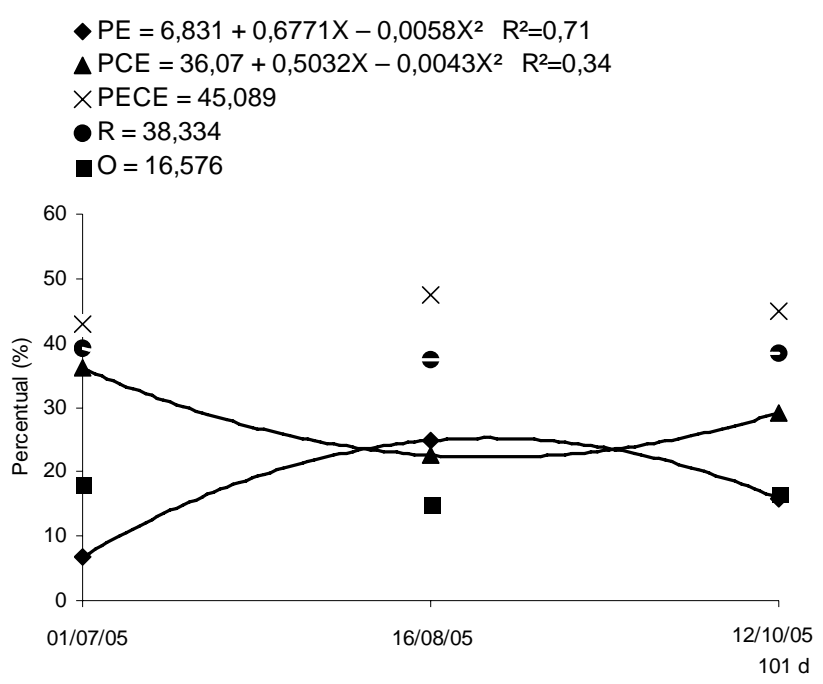

Figura 1 - Tempos de pastejo da entrelinha (PE) e do capimelefante (PCE), tempo de pastejo total (PECE) e tempos de ruminação $(R)$ e ócio $(O)$ de vacas em lactação nos sistemas forrageiros com capim-elefante + trevo-branco + azevém + espécies de crescimento espontâneo (SF1) e amendoim forrageiro + azevém + espécies de crescimento espontâneo (SF2).

pastejo entre as touceiras do capim-elefante, que foi maior no sistema forrageiro com trevo-branco (Tabela 2).

O tempo médio usado pelas vacas na apreensão do capim-elefante não diferiu $(\mathrm{P}>0,05)$ entre os sistemas forrageiros (Tabela 2). Verificou-se, no entanto, efeito quadrático decrescente em ambos os sistemas forrageiros no decorrer dos pastejos. Esse comportamento foi inverso ao do tempo gasto pelos animais no pastejo na entrelinha (Figura 1) e está relacionado à ação cumulativa do frio e das geadas sobre o capim-elefante, especialmente na segunda avaliação, mesmo considerando que as condições climáticas foram mais amenas nesse período em comparação às médias climáticas (Tabela 3). A participação de lâminas foliares dessa forrageira (média dos dois sistemas forrageiros) foi de 37; 20 e 22\% nos três pastejos efetuados. Em pesquisas conduzidas em mesma região, Olivo et al. (2006) verificaram menor participação de lâminas foliares do capim-elefante, de 13,72; 1,72 e 6,52\% em pastejos realizados em julho, agosto e setembro, nos quais foram registradas 4, 9 e 13 geadas cumulativas, respectivamente.

Comparando os modelos de análise de regressão (Figura 1), observa-se que, na segunda avaliação, os animais compensaram o menor tempo disponibilizado no capimelefante (em virtude da menor produção de biomassa de lâminas foliares) pelo maior tempo na entrelinha, evidenciado pelo aumento na produção de forragem do azevém. Na terceira avaliação, embora apresentasse massa de lâminas foliares de capim-elefante, semelhante ao segundo pastejo (Tabela 1), houve maior tempo de acesso dos animais nessa forrageira, possivelmente em razão da maior necessidade de tempo de seleção da brotação em meio ao material senescente das touceiras, que aumentou nos dois ciclos de pastejo finais (Tabela 2).

Os resultados do valor nutritivo nos sistemas forrageiros (Tabela 1) na segunda avaliação foram melhores, o que indica maior tempo de acesso dos animais, em decorrência da maior participação do azevém. Considerando, no entanto, que os animais se mantiveram por mais tempo em pastejo no capim-elefante, pode-se afirmar que essa forrageira apresenta boa qualidade no período hibernal. Essa assertiva foi confirmada por Polli (1992) em trabalho realizado no Rio Grande do Sul, no qual verificou em diversos cultivares de capim-elefante teor de PB de 6,43 em janeiro e de 13,36\% em julho, e por Townsend et al. (1994), que observaram teores crescentes de PB, de 8,9 a 10,9\%, em amostras obtidas por simulação de pastejo entre novembro e março, como média do mesmo cultivar em análise.

O tempo total de pastejo foi de $48 \%$ (9 horas e 36 minutos) e 45,75\% (8 horas e 55 minutos) para os sistemas forrageiros com trevo-branco e com amendoim forrageiro, respectivamente. Esses valores são semelhantes ao encontrado por Olivo et al. (2006), de 9 horas e 16 minutos em experimento com vacas da raça Holandesa e mesma sistemática de complementação alimentar em pastagens de capimelefante consorciado com aveia e azevém. Phillips \& Rind (2001), avaliando o comportamento ingestivo de vacas de mesma raça recebendo diariamente $2 \mathrm{~kg}$ de concentrado em pastejo de azevém perene, verificaram tempo médio de 8 horas e 9 minutos por dia. 
Tabela 3 - Condições climáticas durante o período experimental

\begin{tabular}{|c|c|c|c|c|c|c|}
\hline \multirow[t]{2}{*}{ Variável } & \multicolumn{6}{|c|}{ Período } \\
\hline & \multicolumn{2}{|c|}{ Julho de 2005} & \multicolumn{2}{|c|}{ Agosto de 2005} & \multicolumn{2}{|c|}{ Outubro de 2005} \\
\hline № de geadas cumulativas & \multicolumn{2}{|c|}{1} & \multicolumn{2}{|c|}{6} & \multicolumn{2}{|c|}{7} \\
\hline Temperatura média/mensal $\left({ }^{\circ} \mathrm{C}\right)$ & \multicolumn{2}{|c|}{18,4} & \multicolumn{2}{|c|}{14,2} & \multicolumn{2}{|c|}{21,7} \\
\hline Temperatura média/mensal ${ }^{1}\left({ }^{\circ} \mathrm{C}\right)$ & \multicolumn{2}{|c|}{12,9} & \multicolumn{2}{|c|}{14,6} & \multicolumn{2}{|c|}{18,8} \\
\hline Temperatura média no dia $\left({ }^{\circ} \mathrm{C}\right)$ & 22,2 & 22,8 & 14,9 & 12,4 & 18,4 & 24,5 \\
\hline Temperatura máxima no dia $\left({ }^{\circ} \mathrm{C}\right)$ & 26,0 & 29,6 & 22,2 & 15,8 & 22,2 & 31,8 \\
\hline Temperatura mínima no dia $\left({ }^{\circ} \mathrm{C}\right)$ & 18,4 & 16,1 & 7,7 & 9,1 & 14,7 & 17,3 \\
\hline Umidade relativa no dia (\%) & 59 & 81 & 71 & 95 & 84 & 88 \\
\hline
\end{tabular}

${ }^{1}$ Média climática.

Tempos de pastejo menores foram encontrados, ambos em 24 horas de observação, por Pires et al. (2001), 7 horas e 48 minutos, em pesquisa com vacas em lactação, sem suplementação, em pastagem de Coastcross (Cynodon dactylum), e por Orr et al. (2001), 7 horas e 42 minutos, utilizando vacas da raça Holandesa em pastagem de azevém perene suplementada com concentrado (4 kg/dia).

O tempo de ruminação, na média, não diferiu $(\mathrm{P}>0,05)$ entre os sistemas forrageiros. No sistema forrageiro com trevo-branco, verificou-se interação sistema $\times$ pastejo. $\mathrm{O}$ modelo encontrado, quadrático crescente (Figura 1), está relacionado à maior disponibilidade de massa de forragem de espécies de ciclo hibernal (trevo-branco e azevém, que é mais fibroso) nesse sistema forrageiro, que contribuiu para maior ingestão de matéria seca (Stobbs, 1973), implicando maior tempo de ruminação. O tempo médio de ruminação encontrado, de 39,00\% (7 horas e 48 minutos) e $38,33 \%$ (7 horas e 41 minutos) nos sistemas com trevobranco e com amendoim forrageiro, respectivamente, foi similar aos valores obtidos por Balocchi et al. (2002), que observaram variação entre 7 horas e 20 minutos e 7 horas e 30 minutos, em 24 horas de observação, em pesquisa com vacas em lactação em pastagem de azevém perene suplementada com concentrado (6 kg/dia).

O tempo médio de ócio não apresentou variação $(\mathrm{P}>0,05)$ entre os pastejos e sistemas forrageiros. Os valores obtidos, de 12,98\% ( 2 horas e 36 minutos) e 16,67\% (3 horas e 24 minutos), são inferiores aos relatados por Phillips \& Rind (2001), de 9 horas e 17 minutos; por Orr et al. (2001), que encontraram 9 horas e 5 minutos em avaliações de 24 horas; e aos observados por Olivo et al. (2006), de 5 horas e 8 minutos de ócio em 20 horas de observação. Essas comparações permitem afirmar que os animais demandaram mais tempo para selecionar a dieta, resultando em menor tempo de ócio, em virtude da presença de diferentes plantas forrageiras com ciclos de produção distintos.

\section{Conclusões}

Entre os sistemas forrageiros avaliados, o tempo médio destinado pelas vacas ao pastejo do material forrageiro presente na entrelinha é maior em sistema forrageiro composto de capim-elefante em consórcio com trevo-branco, azevém e espécies de crescimento espontâneo. Em ambos os sistemas forrageiros, a disponibilidade de lâminas foliares do capim-elefante interfere diretamente no tempo destinado pelos animais ao pastejo das espécies estabelecidas na entrelinha. Os tempos de ruminação e ócio são similares, tanto entre os ciclos de pastejo quanto entre os sistemas forrageiros avaliados. Sistemas de pastejo constituídos de espécies forrageiras de ciclos hibernal e estival promovem equilíbrio na disponibilidade e na qualidade da forragem ofertada.

\section{Literatura Citada}

ASSOCIATION OF OFFICIAL ANALYTICAL CHEMISTS - AOAC. Official methods of analysis. 14.ed. Washington, D.C.: 1984. 1094p.

BALOCCHI, O.; PULIDO, R.; FERNÁNDEZ, J. Comportamiento de vacas lecheras en pastoreo com y sin suplementación com concentrado. Agricultura Técnica, v.62, n.1, p.87-98, 2002.

BRÂNCIO, P.A.; EUCLIDES, V.P.B.; NASCIMENTO JR., D. et al. Avaliação de três cultivares de Panicum maximum Jacq. sob pastejo: comportamento ingestivo de bovinos. Revista Brasileira de Zootecnia, v.32, n.5, p.1045-1053, 2003.

CARVALHO, P.C.F.; RIBEIRO FILHO, H.M.N.; POLI, C.H.E.C. Importância da estrutura da pastagem na ingestão e seleção de dietas pelo animal em pastejo. In: MATTOS, W.S. (Ed.) A produção animal na visão dos brasileiros. Piracicaba: Fundação de Estudos Agrários Luiz de Queiroz, 2001. p.853-871.

COSTA, C.O.; FISCHER, V.; VETROMILLA, M.A.M. et al. Influence of progressive defoliation of a grass sward on the eating behaviour of cattle. Australian Journal Agricultural Research, v.27, p.709-727, 1976.

COSTA, C.O.; FISCHER, V.; VETROMILLA, M.A.M. et al. Comportamento ingestivo de vacas Jersey confinadas durante a fase inicial da lactação. Revista Brasileira de Zootecnia, v.32, n.2, p.418-424, 2003.

EMPRESA BRASILEIRA DE PESQUISA AGROPECUÁRIA EMBRAPA. Sistema brasileiro de classificação de solos. Brasília: Centro Nacional de Pesquisa de Solos, 1999. 412p. 
EUCLIDES, V.P.B.; MACEDO, M.C.M.; OLIVEIRA, M.P. Avaliação de diferentes métodos de amostragens sob pastejo. Revista Brasileira de Zootecnia, v.21, n.4, p.691-702, 1992.

FISCHER, V.; DESWYSEN, A.G.; DUTILlEUL, P. et al. Padrões da distribuição nictemeral do comportamento ingestivo de vacas leiteiras, ao início e ao final da lactação, alimentadas com dieta à base de silagem de milho. Revista Brasileira de Zootecnia, v.31, n.5, p.2129-2138, 2002.

GONYOU, H.W. Why the study of animal behavior is associated with the animal welfare issue. Journal of Animal Science, v.72, n.8, p.2171-2177, 1994.

GRANT, R.J.; ALBRIGHT, J.L. Feeding behaviour and management factors during the transition period in dairy cattle. Journal of Animal Science, v.73, n.9, p.2791-2803, 1995.

KUNKLE, W.E.; BATES, D.B. Evaluating feed purchasing options: energy, protein, and mineral supplements. In: FLORIDA BEEF CATTle ShORT COURSE, 1998, Gainesville. Proceedings... Gainesville: University of Florida, 1998. p.59-70.

MANUAL DE ADUBAÇÃO E CALAGEM PARA OS ESTADOS DO RIO GRANDE DO SUL E SANTA CATARINA. Porto Alegre: SBCS, 2004. 394p.

MENDONÇA, S.S.; CAMPOS, J.M.S.; VALADARES FILHO, S.C. et al. Comportamento ingestivo de vacas leiteiras alimentadas com dietas à base de cana-de-açúcar ou silagem de milho. Revista Brasileira de Zootecnia, v.33, n.3, p.723-728, 2004.

MORENO, J.A. Clima do Rio Grande do Sul. Porto Alegre: Secretaria da Agricultura, 1961. 41p.

OLIVO, C.J.; CHARÃO, P.S.; ZIECH, M.F. et al. Comportamento de vacas em lactação em pastagem manejada sob princípios agroecológicos. Revista Brasileira de Zootecnia, v.35, n.6, p.2443-2450, 2006.

ORR, R.J.S.; RUTTER, S.M.; PENNING, P.D. et al. Matching grass supply to grazing patterns for dairy cows. Grass and Forage Science, v.56, n.35, p.352-361, 2001.

PERISSINOTTO, M.; MOURA, D.J.; MATARAZZO, S.V. et al. Behavior of dairy cows housed in environmentally controlled freestall. Agricultural Engineering International: the CIGR Ejournal, v.3, p.5-16, 2006.

PHILLIPS, C.J.; RIND, M.I. The effects of social dominance on the production and behavior of grazing dairy cows offered forage supplements. Journal of Dairy Science, v.85, n.1, p.51-59, 2001.

PIRES, M.F.A.; VILELA, D.; ALVIM, M.J. Comportamento alimentar de vacas holandesas em sistemas de pastagens ou em confinamento. Juiz de Fora: EMBRAPA Gado de Leite, 2001. 2p. (Boletim Técnico, 2).

POLI, C.H.E.C. Desenvolvimento morfológico, produção de forragem, proteína bruta e digestibilidade in vitro de cinco cultivares de capim-elefante (Pennisetum purpureum, Schum.). Porto Alegre: Universidade Federal do Rio Grande do Sul, 1992. 148p. Dissertação (Mestrado em Zootecnia) Universidade Federal do Rio Grande do Sul, 1992.

POLLI, V.A.; RESTLE, J.; SENNA, D.B.L. Comportamento de bovinos e bubalinos em regime de confinamento. I. Atividades. Ciência Rural, v.25, n.1, p.127-131, 1995.

RAY, D.E.; ROUBICECK, C. B. Behaviour of feedlot cattle during two seasons. Journal of Animal Science, v.33, n.1, p.46-51, 1971.

STATISCAL ANALYSIS SYSTEM - SAS. User's guide: statistics, Version 6.12, Cary: SAS Institute, 1997. (CD-ROM).

STOBBS, T.H. The effect of plant structure on the intake of tropical pasture. 2. Differences in sward structure, nutritive value, and bite size of animals grazing Setaria anceps and Chloris gayana at various stages of growth. Australian Journal of Agricultural Research, v.24, n.6, p.821-829, 1973.

STOBBS, T.H. Milk production, milk composition, rate of milking and grazing behavior of dairy cows grazing two tropical grass pasture under a leader and follower systems. Australian Journal of Experimental Agriculture and Animal Husbandry, v.18, n.1, p.5-11, 1978.

TILLEY J.M.A.; TERRY, R.A. A two-stage technique of the "in vitro" digestion of forage crop. Journal of the British Grassland Society, v.18, n.2, p.104-111, 1963.

TOWNSEND, C.R.; OLIVO, C.J.; RUVIARO, C.F. Desempenho de novilhas da raça Holandesa em cultivares de capim-elefante (Pennisetum purpureum Schum.). Ciência Rural, v.24, n.2, p.381-386, 1994.

TREVISAN, N.B.; QUADROS, F.L.F.; SILVA, A.C.F. et al. Efeito da estrutura de uma pastagem hibernal sobre o comportamento de pastejo de novilhos de corte. Revista Brasileira de Zootecnia, v.34, n.3, p.774-780, 2005.

Van SOEST, P.J.; ROBERTSON. J.B.; LEWIS, B.A. Methods for dietary fiber, neutral detergent fiber, and nonstarch polysaccharides in relation to animal nutrition. Journal of Dairy Science, v.74, n.1, p.3583-3597, 1991.

WILM, H.G.; COSTELLO, D.F.; KLIPPLE, G.E. et al. Estimating forage yield by the double-sampling methods. Journal American Society Agronomy, v.36, p.194-203, 1944. 